\title{
Languagehood of Cantonese: A Renewed Front in an Old Debate
}

\author{
Siu-Pong Cheng, Sze-Wing Tang \\ The Chinese University of Hong Kong, Hong Kong, China \\ Email: spcheng@cuhk.edu.hk, swtang@cuhk.edu.hk
}

Received 24 May 2014; revised 28 June 2014; accepted 10 July 2014

Copyright (C) 2014 by authors and Scientific Research Publishing Inc.

This work is licensed under the Creative Commons Attribution International License (CC BY). http://creativecommons.org/licenses/by/4.0/

cC) (i) Open Access

\section{Abstract}

This paper studies the discourses that underlie the controversy in the first half of 2014 over the status of Cantonese in Hong Kong. It turns out that the factors of mutual intelligibility and hard power are insufficient for this language/dialect debate. The writing system and literary tradition of Chinese complicate the status and identity issues of Cantonese. These complicating factors are language-specific in the sense that the orthographic depth and the "elegant" standard might differ significantly across languages. Added to these is the semantic complication that the meaning of terms varies not just because of translation, but also that there are alternative ways to conceptualize them. This paper concludes that the definition of linguistic terms like "language" and "dialect" is becoming more and more in the hands of the people. Recent developments in communication have brought the debate in Hong Kong to a new level. It is expected to be the trend of how sociolinguistic topics are pursued.

\section{Keywords}

Cantonese, Language, Dialect, Orthography, Register

\section{Introduction}

In early 2014, an article was posted on Hong Kong Education Bureau's website stating that Cantonese is "a Chinese dialect that is not an official language". It quickly became an immediate cause of the recent controversy over the status of Cantonese in Hong Kong ${ }^{1}$. This statement raised two questions that would be hotly debated over the following months: 1) Is Cantonese (just) a Chinese dialect? and 2) Is Cantonese not an official language?

\footnotetext{
${ }^{1}$ Structural causes relate to Hong Kong’s political situation in recent years. Most notably, it involves the relations between Hong Kong and the mainland of China. See the relevant section in the South China Morning Post for the political raison d'être of this event (http://www.scmp.com/topics/hong-kong-mainland-relations).
} 
It appears that there is an easier answer to the second question. Since the handover of Hong Kong to China in 1997, Cantonese is used by all Hong Kong's heads of government (Chief Executives) in their annual policy address, and the majority of discussions taking place in the post-handover Legislative Council meetings have been given in Cantonese (English comes second). There is little doubt that Cantonese is Hong Kong's de facto official language. At issue is whether it is de jure official. As will be seen below, an answer to this second question depends on how the relationship between such terms as "Cantonese" and "Chinese" is addressed, meaning that the first question is pivotal. To discuss the language-/dialect-hood of Cantonese, this paper is organized as follows. Sections 1.1 and 1.2 present the two common criteria that determine if a variety is a language or a dialect, namely, mutual intelligibility and politics. It turns out that they are respectively resorted to by people who stand on different sides of the language/dialect debate. Section 2 is devoted to those complicating factors that blur the distinction made between these two criteria. Section 2.1 addresses the particularity of the Chinese script. Section 2.2 recalls various discussions on the linguistic "purity" of Cantonese. Section 2.3 touches upon the fundamental issues underlying the recent controversy: Are we arguing over the same notion? The theme of this paper is to highlight the significance of the so-called "folk beliefs" that very often supersede any attempts to define language/dialect in an academic (or "pedantic" for that matter) manner.

\subsection{Mutual Intelligibility}

Cantonese is defined as a language given that it is mutually unintelligible with another Chinese variety, e.g., Mandarin. It has been well known that Chinese is not a single language in the sense that all its speakers can understand one another. Significant sound variation suffices to divide Mandarin and Cantonese, not to mention other differences in lexicon and grammar. Hou (2002: 188) notes that around two thirds of the basic Cantonese words are "same" as those used in the "national common language" (i.e., Mandarin or Putonghua). We can regard that by "sameness," it means these words are cognates sharing a common source. Nonetheless, even if Cantonese speakers limit their vocabulary to these two thirds or so of basic words, this Cantonese variety is still intelligible to Mandarin speakers to a very low degree, provided that they have no previous exposure to it. Therefore, it is fair to say that "Cantonese differs from Mandarin to much the same extent as French differs from Spanish, or Swedish from German” (Matthews \& Yip, 2011: 6). The heartlands of other Chinese varieties, such as the Min and Hakka "dialects," are much closer to the core Cantonese-speaking region than Mandarin-speaking Beijing is to Cantonese-speaking Guangzhou or Hong Kong. But still Min and Hakka are unintelligible to Cantonese and may sound just as foreign to a native ear. So far, mutual intelligibility is the strongest "linguistic" evidence to prove the language status of Cantonese. It is clearly an abstand language (in the definition of Kloss, 1967) with respect to another Chinese variety, e.g., Mandarin. In this regard, "Chinese" is more a language family than a single language, sometimes known as the Sinitic languages. At issue is whether Cantonese in a broad sense is a single language. Depending on the extension of the word, the term "Cantonese" may be used for just any variety within the "Yue Dialect Group"2. Hong Kong and Guangzhou Cantonese belong to the Guangfu Branch of Yue. In addition to this Yue Branch, there are a few more branches that might share the label “Cantonese.” They include Siyi, Gao-Yang, Guan-Bao, Goulou, Xiangshan, Guinan, and Wu-Hua, etc., depending on different classification systems (see Zhan, 1991, 2002; Yuan et al., 1960/2001; Li, 1994; and Language Atlas, 1987, 2012 for different classification schemes). The mutual intelligibility between Cantonese as used in Hong Kong and Guangzhou and some varieties in these other branches can be marginal. This problem can be solved if Cantonese is restricted to mean Hong Kong/Guangzhou Cantonese.

\subsection{Politics}

In the beginning of their book, Chambers and Trudgill (1998/2004) depict the difficulties with the criterion of mutual intelligibility: it admits of degrees of more or less, it is not equal in both directions, and it depends on the listeners' exposure to or even their willingness to understand the other language (2004: 3-4). They also indicate the common fact that political factors often override this criterion. The old saying that "a language is a dialect with an army and a navy" (attributed to Max Weinreich) appears in almost every textbook on sociolinguistics, showing that the distinction between language and dialect is at least partly politically driven or even it involves realpolitik. Let's assume that a variety is a language only when the government decides so. Cantonese is spoken

\footnotetext{
${ }^{2}$ Notwithstanding this possibility, Cantonese commonly refers to Guangzhou/Hong Kong Cantonese.
} 
by around 4 to 5 percent of China's 1.3 billion people. Language Atlas (2012) gives a figure of 59.58 million speakers. It is the predominant variety spoken in Hong Kong and Macao. In addition, it is inferred from the recent statistics that over 5 percent of Malaysia's population can speak Cantonese with varying degrees of fluency (according to Tan (2005: 689), in 2001, 24.45\% of Malaysia's population are ethnic Chinese, and 19.90\% of Malaysian Chinese are from the Cantonese speech group (2003 figure). It is also well known that Cantonese is a popular second language there). In Singapore, out of approximately three million of the resident population, 386,000 were identified as belonging to the Cantonese dialect group, out of which some 36 percent of them spoke Cantonese most frequently at home (2000 figure from Lee, 2001). Canada, Australia, New Zealand, and the United States also have a less but significant proportion of Cantonese speakers. Cantonese is not a national language in any of the above-mentioned countries, and no national or sub-national entities here explicate in their constitutional documents that "Cantonese” (the exact wording) is an official language. In Hong Kong's constitutional Basic Law, it states that "[i]n addition to the Chinese language, English may also be used as an official language by the executive authorities, legislature and judiciary of the Hong Kong Special Administrative Region" (Article 9). Macao's Basic Law has a similar article, with "English” replaced by "Portuguese." Earlier in 1974, a local law was introduced in Hong Kong recognizing "Chinese" as an official language. As noticed by many scholars (e.g., Bauer, 2000), the term "Chinese" is "ambiguous, as it can refer to just any kind of Chinese, that is, its written forms, such as classical, modern vernacular, dialectal, and its spoken forms, including Putonghua and any of the Chinese dialects, such as Cantonese” (Bauer, 2000: 38). Even if Cantonese attains de jure status through its association with Chinese, it is, in so doing, viewed as more heteronomous than autonomous with respect to Chinese. In the mainland of China, the ambiguity is less of a problem: the Law of the People's Republic of China on the Standard Spoken and Written Chinese Language, effective 2001, states that "[f]or purposes of this Law, the standard spoken and written Chinese language means Putonghua (a common speech with pronunciation based on the Beijing dialect) and the standardized Chinese characters" (Article 2) ${ }^{3}$. It is easy to conclude from this law and other current official policies that Cantonese as used in the mainland of China is a "local dialect" according to the Chinese government. The strict adherence to the "army-and-navy" metaphor renders that Cantonese is more difficult identified as an ausbau language (Kloss, 1967) than it is regarded as an abstand language, no matter where it is used.

\section{Some Complicating Factors}

There is a great deal of truth in the Weinreichian notion of "language." Nonetheless, as in all metaphors, the tertium comparationis here (i.e., power) is always subject to varying interpretation. At the federal level, the United States has never set an official language. It is rather counterintuitive to suggest, however, that English in America does not hold its language status or such status is derived from being the de jure official language of a particular state (e.g., Florida) or another country (e.g., Bahamas). Certainly, autonomy is not a purely linguistic concept. Yet neither is autonomy a purely political concept for it is fully tied to policymaking. So far, we see that mutual intelligibility goes for the languagehood of Cantonese, but the force and will of the government(s) does not. There are in fact other factors that may blur the intelligibility-versus-power dichotomy, a division well discussed in Hong Kong's newspaper columns since the incident mentioned at the beginning of this paper. (Bell 1976; quoted in Wardhaugh, 1998: 29-37) indicates seven criteria that can be used to distinguish certain languages from others. They are standardization, vitality, historicity, autonomy, reduction, mixture, and de facto norms (see Bell, 1976: 145-163 for details). Based on Bell's typology, Groves (2008: 51) places Cantonese half-way between standard language and dialect, below the type of classical (King James' Bible English as Bell's example) and above the type of vernacular (Black English as the example). It follows that some of these criteria, such as historicity (related to identity) and mixture (related to linguistic "purity") are more relevant to our discussions of the current controversy. Many of these criteria lay stress on the mentality of the populace, and as we will see further, they are rather language-specific. Wardhaugh speaks of Bell's autonomy criterion as "an interesting concept because it is one of feeling" (1998: 35). This interpretation of autonomy accommodates the case of Hong Kong Cantonese as attested in this era ${ }^{4}$.

\footnotetext{
${ }^{3}$ This law, as well as the vast majority of other national laws, does not apply in Hong Kong and Macao.

${ }^{4}$ This view resonates with a recent talk by Sun Chaofen (2014) titled “Dialect or Language: A Matter of Language Attitudes.” And Groves' survey of Cantonese speakers was taken in response to the claim that "[t]he attitude of the speakers themselves is usually said to be the deciding factor...” (2008: i).
} 


\subsection{Writing System}

It is not a new idea that the Chinese characters might be linked to the unity of China over an extensive period of time. As argued by famous writer Bo Yang in his book Zhongguoren Shigang [A Historical Outline of the Chinese People] (1979/2002: 576), China does not employ the alphabetical system as used in the Latin script, in which case geographical separation led to the spelling out of individual languages; by contrast, the Chinese characters act as an "invisible magic wire" that connects different languages. He further suggests that if the Latin script were not alphabetical but something like the Chinese characters, "Europe would have long been unified as a single country.” More explicitly, Dang (1980: 84-85) points out that the unity of written language, together with other factors, led to the result that Cantonese is considered a Chinese dialect. The idea of "one written form (in Chinese characters) for many spoken varieties” have lingered on Chinese for a continuous period of over two thousand years, even from the 1920s on when the common written form began to change from the one based on Classical Chinese to the one based on the vernacular. This written vernacular, or baihuawen, is based on the northern Chinese variety. Simply speaking, it is based on Mandarin. Standard written Chinese as used in Hong Kong is essentially the same one used by all literate Chinese speakers worldwide. Shi et al. (2006) offer a comparative study between standard written Chinese and its Hong Kong variant and identify several distinctive features of the latter arisen as a result of Cantonese influence. This Hong Kong-style written Chinese, as they point out, is by and large intelligible to non-Cantonese speakers, and it differs from another written form which they call Cantonese (written) Chinese. In his comprehensive study of written Cantonese and its use in Hong Kong, Snow (2004) indicates that most of Hong Kong's written Chinese communication, including almost all official communication, takes place in standard Chinese, and that written Cantonese is limited to informal and less serious types of communication (2004: 18). He uses diglossia as an explanatory tool and classifies the former as the $\mathrm{H}$ variety and the latter as the $\mathrm{L}$ variety ${ }^{5}$. It appears that from orthography to the actual use, evidence from the written systems is presented against Cantonese being a "superior” variety. In the spirit of Bell (1976) and Wardhaugh (1998), this condition may lead to reduction, the case where a variety is regarded as a sub-variety and not an independent entity. Wardhaugh's examples include Cockney English: “[s]peakers of Cockney will almost certainly say they speak a variety of English” (1998: 35). Not surprisingly, when Cantonese speakers in Hong Kong are asked what they speak, many might say they speak zungman "Chinese” (though gwongdungwaa "Cantonese" is also possible) ${ }^{6}$. In addition to reduction, the lack of standardization (What is the standard way to write a particular Cantonese-specific character?) and norms (Who writes the best Cantonese?) offers another prima facie evidence against Cantonese as a full-fledged written language ${ }^{7}$ Having a superior, codified writing form might not be a necessary condition for languagehood. Yet, it is natural to consider it a sufficient condition.

Written Cantonese is not a new phenomenon arisen a few years ago. According to Snow (2004: 98), it had already developed significantly in several ways by the 1930s. A literary tradition that uses Cantonese arguably exists. Recent developments are characterized by the rise of online communities with a clear manifesto to promote its literary tradition. It remains to be seen whether substantial progress can be made. Even if these efforts turn out to be hugely successful, the further rise of written Cantonese will follow the usual pathway that writing empowers a variety. What is special about the influence of the Chinese writing system on Cantonese is that the whole set of arguments about Cantonese being a “deficient” variety can be repackaged to the opponents' advantage. Chinese characters are a logographic writing system. Although the standard definition of logographic writing, i.e., "each graphic unit represents a morpheme” (Lyovin, 1997: 31), does not hold true for every character, this labeling captures the essence of the Chinese script. As a logographic writing, the Chinese characters can be classified as a deep orthography. The "shallow" and “deep” orthographies (Klima, 1972) are understood as follows: in a shallow orthography, there is almost one-to-one relationship between sounds and words, whereas in a deep orthography, the relationship between sounds and words is more complex (Sebba, 2007: 19). Sebba exemplifies the deep orthography of English by words like soul and sole. The case where one sound unit corresponds to different graphemes is also shared by the Chinese characters. They should also be regarded as a deep orthog-

\footnotetext{
${ }^{5}$ Hong Kong is also diglossic in that English is the $\mathrm{H}$ variety; for the sake of relevance, the diglossia associated with English will not be further pursued in this paper.

${ }^{6}$ The romanization of Cantonese in this paper is based on Hong Kong Cantonese and follows the Linguistic Society of Hong Kong (LSHK) Cantonese Romanization Scheme, also known as jyutping. The romanization of Mandarin and standard written Chinese is given in pinyin.

${ }^{7}$ There are indeed some efforts to standardize the Chinese characters for written Cantonese. For lack of government-sponsored initiatives, however, these efforts are insufficiently coordinated.
} 
raphy for its complex relationship between phonemes and graphemes ${ }^{8}$. The resulting non-transparency as seen in the Chinese characters is overwhelming-other typical "deep" orthographies, such as the English one, become rather "shallow" vis-à-vis the Chinese characters. Reading a Mandarin text in Chinese characters with their Cantonese pronunciations is totally dissimilar to the situation where one reads aloud a French text in Spanish (recall the French-Spanish vs. Mandarin-Cantonese variation). In most cases, there is no sign in a Chinese character to show that the Mandarin pronunciation is preferred over the Cantonese one, or the other way around ${ }^{9}$. The character for "human," for example, could be read as naturally as ren (Mandarin) or jan (Cantonese). By contrast, reading out the French word humain in its French pronunciation makes much more sense than it is read as Spanish humano. In Hong Kong's schools, studying standard written Chinese read with their Cantonese pronunciations has been and is still a common practice. This is made possible largely because of the orthographic depth of the Chinese characters. No one actually "speaks" this Cantonese-pronounced standard written Chinese, but neither is such act thought of as unworkable. The typical diglossia between standard written Chinese and written Cantonese can be easily construed as another notion. The original proposal by Ferguson (1959) discusses four examples: the Arab World (H: Classical Arabic; L: Dialectal Arabic), Switzerland (H: Standard German; L: Swiss German), Greece (H: katharevousa; L: dimotiki), and Haiti (H: French; L: Haitian Creole). Fishman (1967) provides another example: Paraguay (H: Spanish; L: Guaraní). Both Ferguson and later works (e.g., Kaye, 1991) offer diglossic parallels in English (purchase vs. buy). Obviously, the genetic relationship between Spanish and Guaraní of South America is much more distant than that of Ferguson's examples, so Fishman's diglossia is often called "broad diglossia" in the sociolinguistic literature. Fasold (1984: 54) classifies broad diglossia into three subtypes: superposed bilingualism (between separate languages), classic diglossia (between divergent varieties), and style shifting (stylistic variation). They correspond respectively to the cases of Spanish-Guaraní in Paraguay, German in Switzerland, and English in America. In this regard, diglossia can be treated as a continuum with one end represented by Außendiglossie (external diglossia) and another end by Binnendiglossie (internal diglossia) (terms borrowed from Kloss, 1976). Hong Kong’s diglossia as mentioned above is, academically, a "classic" one. However, the opacity of Chinese characters and the possibility of reading standard written Chinese in Cantonese allow people to think of this diglossia as more like style shifting. Cantonese is still considered a spoken variety, or haujyu (Mandarin: kouyu) "spoken language,” whereas standard written Chinese becomes its literary counterpart, known as syuminjyu (Mandarin: shumianyu) "written language." This is the most common treatment as we see in Hong Kong nowadays. While it is hard to consider this syuminjyu variety as an integral part of Cantonese, with this view in mind, it is not considered as "foreign" or "superposed" either. In other words, the nature of Chinese characters masks a greater difference between standard written Chinese and Cantonese, allowing their division of labor to be more viewed as internal than as external diglossia, or just style shifting. So an argument against Cantonese being a sub-variety can be made by saying that nothing is superior to it, and all that matters is language style.

\section{2. "Chineseness"}

In an online article titled "Bouwu Gwongdungwaa, Msai Gong Jyunjan” [Protecting Cantonese Needs No Justification] (PCNNJ), its author (known as Zaakjin) tries to dispel some myths associated with Cantonese, on whether Cantonese was spoken around a millennium ago in the Tang Dynasty (618-907 CE), and whether Cantonese is a "pure" Chinese in sharp contrast to Mandarin (Putonghua)-a Manchu language. In this paper, it is confirmed from personal experience that these tales are quite mundane. They relate to the issues of historicity and "purity" (or "mixture" in Bell's term). For obvious reasons, Cantonese has never fulfilled the two conditions that might (barely) keep it intact and "pure" over hundreds of years: 1) codification and its strong enforcement; and 2) complete isolation from other speech communities. The misconceptions as identified in PCNNJ that Cantonese has not changed for a long time and it has not incorporated words from other languages are convincingly refuted by the author. In the recent controversy, "how long" Cantonese is and "how much" it is "Chinese"

\footnotetext{
${ }^{8}$ There are more instances of one-to-one correspondence from characters to sounds than from sounds to characters. The deep orthography is taken to mean the complexity in either or both directions.

${ }^{9}$ Simplified characters, however, further complicate the matter as many characters were simplified by replacing the whole character (or part of it) with another character (component) that sounds the same in Mandarin, rather than in Cantonese. Besides, the adoption of simplified characters was implemented in the mainland of China in 1956, after the founding of the People's Republic of China when the political separation across the Taiwan Strait occurred. Taiwan, Hong Kong, and Macao have continued to use traditional characters. The use and view of simplified characters is destined to be highly politicized.
} 
have become relevant to the language/dialect debate. But long before this, academic discussions had brought the issue to center stage. J. Li (1990) makes explicit that Cantonese is an "independent language in the family of Chinese languages." Unlike an earlier, more common view that "Chinese is not a single language but a family of languages made up of a variety of mutually unintelligible languages" (Bloomfield, 1933: 44; quoted in DeFrancis, 1984: 54), Li argues that Northern, Xiang, Gan, and Hakka dialects belong to "Chinese" (Hanyu), and that $\mathrm{Wu}$, Min, and Yue dialects should be re-classified as separate languages within the Chinese language family (1990: 29). Given that Northern, Xiang, Gan, and Hakka dialects are all mutually unintelligible, it can be seen that mutual intelligibility is not the only measure he uses to determine the languagehood. One of Li's arguments is that there are more in their difference than sameness between Yue (Cantonese) and Mandarin (Putonghua). Another one is based on his claim that modern Cantonese has developed by mixing Old Chinese with Old Yao and Old Zhuang-Dong (Tai-Kadai), a process started from the third century BCE when substantial numbers of Han Chinese moved southward to Lingnan, part of which has become now the core area of Yue. Whereas the influence of non-Han languages on Cantonese is less disputable (for more evidence, see Yue-Hashimoto, 1976, 1991; Chishima, 1983; Bauer, 1987, etc.), it is still a matter of great debate about when the divergence of Yue from other Chinese varieties occurred. Lau (2000: 81) posits a much later time for the divergence: less than a thousand years from the Northern dialects and no more than seven hundred years from Hakka and Gan dialects. In addition to the linguistic evidence, he also offers statistical data to show that the population of Guangdong (including its main port Guangzhou) increased six times from the end of the tenth century to the end of the eleventh century (2000: 78). Therefore, he argues that modern Yue is not a direct decedent of Old Yue; instead, language shift arisen from later migration was vital to its formation. As can be seen, the gap between the two proposed divergence times (Li's and Lau's) can be as long as 1500 years ${ }^{10}$.

As far as historical factors are concerned, two ideas are deemed conducive in order to enhance the autonomy of a variety: 1) it diverged from the "mother variety" as early as possible; and 2) it is as genetically different as possible from other varieties of the same "roofing language." A variety may derive its prestige from its long history and/or the particularity in its emergence. In Spain, Basque and Catalan are good examples to illustrate the prestige factor (The case of Spain is especially remarkable as the non-Castilian languages were always referred to as a "dialect" under Franco's dictatorship; see Mar-Molinero, 2000: 80). Nevertheless, the prestige of Cantonese is not always built on the factors of "divergence" or "mixture." Rather, it is often valued for the lack of them. The usual compliment includes "classic elegance," or gu'ngaa (Mandarin: guya; see Zeng, 2008: 215, Ho, 2008: 137, among others). This idea can be comprehended in phonetic, lexical, and syntactic terms. Languages always change, but in the case of Cantonese, the vowels in Middle Chinese align well with the subsequent vowel change pattern, so much so that a poem written in that period (a millennium ago, for instance) still rhymes in modern Cantonese. Another feature is the retention of the traditional tonal category called the "Entering tones." In modern Cantonese, they are expressed in a form containing a coda from /p, t, k/. Mandarin, by contrast, varies more greatly from the Middle Chinese sound system. To this, Bauer (2000) illustrates the closer resemblance of Cantonese (as compared to Mandarin) to Middle Chinese with a lyric poem from the thirteenth century CE and concludes that "the modern Cantonese phonological system which speakers carry around in their heads resembles more closely the ancient Chinese sound system than does Putonghua could or even should be just one more reason why Cantonese speakers need not be made to feel guilty about speaking Cantonese" (2000: 80). In the lexical aspect, best-selling writer Chin Wan published a series of works advocating the proper use of Chinese, whereby he also suggests that Cantonese be protected for the sake of "conserving the Chinese language" (Chin, 2010: 238). The Cantonese vocabulary, as he points out, keeps the ancient taste of simplicity and conciseness. Same as Bauer (2000), these assertions are made in the discourse that Cantonese is contrasted with Mandarin. In his another book, Chin (2012: 65-68) criticizes the use of Mandarin rang in written Chinese, partly due to his claim that it originated from the Altaic language family. Given that rang is a highly grammaticalized linguistic item, this view can be taken as his stand on "syntactic elegance"". Similar statements on the elegance

\footnotetext{
${ }^{10}$ In an earlier work, Chishima (1983: 15) also notes that migration of Han Chinese from the homeland in the North to Guangdong was intense during the end of the Song Dynasty and the beginning of the Yuan Dynasty (around the second half of the thirteenth century CE). X. Li (1994) in general shares the same view as J. Li’s (1990), yet he also notes that Yue, as he figuratively puts it, "had grown up” and eventually "struck out on its own" during the Tang Dynasty and later the Song Dynasty.

${ }^{11}$ Chin suggests that rang is a verbal suffix, which is more found in the Northern than the Southern dialects, and there were few such suffixes in Classical Chinese prior to the Han Dynasty (206 BCE-220 CE) (2012: 66). In more syntactic terms, it relates to the broader issue of Chinese analyticity and syntheticity. See Huang (to appear). The syntactic elegance can be understood as a preference of the (relative) syntheticity found in Classical Chinese over the (relative) analyticity in modern Mandarin.
} 
of the Cantonese speech (addressed in comparison to the Mandarin one) are frequently found in Hong Kong's newspaper columns and online posts. There are some puzzles that need to be resolved, though. First, Cantonese as suggested is elegant in some or most of its words, but how does this notion accommodate the fact that it is mostly used in informal written communication? Second, modern standard written Chinese, a Mandarin-based variety, does (at least to many people's perception) carry some prestige over Cantonese as it is used in formal contexts; how can the prestige of Cantonese be maintained in spite of this fact? Following Feng $(2009,2010)$, the apparent conflicts between formality and elegance is illusionary. Feng formulates two axes for the theory of "register" (he tentatively terms it for Chinese yuti): one relates to formal-informal units, and another to elegant-casual units. While such term as "(in) formal" is self-explanatory, "elegance" is achieved "when some of the words, while being comprehensible, are taken from Classical Chinese" (2010: 402). This "Cartesian" system for register studies implies that an informal (colloquial) register can be elegant, so can the formal register be "casual." A large number of popular books on Cantonese colloquialism have been published over these years, all suggesting that Cantonese is lively and vivid. The formality factor plays a role in shaping this perception. What is further proposed is that, thanks to its elegance, speaking Cantonese is also a graceful thing to do. By the same token, the form of modern standard written Chinese as seen nowadays is often criticized for the lack of elegance. Thus, the overt prestige (prestige of being high-status) enjoyed by this variety should be challenged, and a written standard closer to the Classical Chinese norms upheld. This "elegant-casual" axis as proposed by Feng does not come into existence unless there is a visible literary tradition. As far as the case of Cantonese is concerned, this tradition which now people resort to is a "Chinese" one ${ }^{12}$. Together with the "Manchu" myth laid upon Mandarin, plus some real evidence of the Manchu influence on it, the "Chineseness" factor has brought the language/dialect debate to a different dimension. Though it does not offer much in favor of the languagehood of Cantonese, it is a good defense strategy against any claim for its dialecthood, which some consider undesirable. Expressed in a personified manner with Cantonese addressing to Mandarin, it would be like: "Don't call me dialect. I'm more Chinese than you are!”

\subsection{A Matter of Semantics}

The old language/dialect debate is also complicated by the very meaning of these two terms, and much so if it involves cross-linguistic interaction. Most Chinese-language publications describe Cantonese as a "dialect" in the sense that it is the translation of fangyan "regional speech." Another commonly-used term is difanghua "local speech." As expected, Chinese- and English-language discourses do not use these terms to convey the same denotative meaning. DeFrancis (1984) notices the possible semantic discrepancies between "dialect" and fangyan and coins a new term "regionalect." He indicates that "[s]ince fängyán is literally 'regional speech,' we would either adopt this designation or coin an abbreviation such as 'regionalect' for the mutually unintelligible varieties of Chinese. The term 'dialect' can then be reserved for its usual function of designating mutually intelligible subvarieties of the regionalects” (1984: 57). In the same vein, Mair (1991) addresses the same problem and suggests "topolect" as an alternative to regionalect, "which—aside from being fully Greek in its derivationhas the added advantage of being neutral with regard to the size of the place that is designated whereas 'region' refers only to a rather large area" (1991: 7). Regarding this, Groves (2008: 33) comments that Mair's idea is to delink fangyan and "dialect" altogether.

It appears that a good, faithful translation overcomes all semantic hurdles, but the sad fact is that it does not. Even in English, both the sociolinguistic and the common "dictionary" definitions of "language" and "dialect" do not accord well with some people's perception of them. "Dialect," as defined in a sociolinguistic textbook, is a "variety of a language used recognizably in a specific region or (a social dialect) by a specific social class" (Spolsky, 1998: 122), whereas "variety" is a "term used to denote any identifiable kind of language" (1998: 126). Variety is superordinate to dialect, which itself is a hyponym. The "kind-of" relation between language and variety means that variety is a hyponym of language, so dialect is a hyponym of language by transitivity. Just before discussing the complexity of their relationship, Crystal (2008: 142) also comments that "[t]he distinction between 'dialect' and 'language' seems obvious: dialects are subdivisions of languages." To understand these notions in terms of hyponymy-hypernymy, however, becomes a problem when, in common usage, they are often thought of as incompatibles. A hyponym (dog) entails the superordinate (animal), but often in daily usage, a dialect is not a language, and such kind of entailment is practically unacceptable. The ordinary "dictionary"

\footnotetext{
${ }^{12}$ The Cantonese literary tradition exists (see Snow, 2004 for details) but is not the one resorted to.
} 
definition does not help either. Trousdale (2010) cites the definition of dialect from the online version of the Oxford English Dictionary (www.oed.com): "Dialect... Also in a wider sense applied to a particular language in its relation to the family of languages to which it belongs." And he points out that "the last part of the definition of dialect suggests that one meaning of dialect is 'language'!" (2010: 5; note that the exclamation mark is his own). This part of the definition rejects the view that a dialect can never be a language. The same idea of their being incompatible also exists in the case of fangyan and yuyan "language," regardless of how they are translated. For those who referred to the previous literature in linguistics, they readily notice the problem of such opposition. In 2010, blogger Tutengzi posted an influential article indicating that it is a bad question to ask if Cantonese is yuyan or ("exclusive" or) fangyan because, depending on who and how to define them, Cantonese can be classified either way, so on the whole it is both yuyan and fangyan. In an interview reported in Shawbeat, Tang (2014) exemplifies the compatibility of these terms by stating that Cantonese is fangyan according to Yuan et al. (1960/2001) and yuyan in the classic Chomskyan view. What Tutengzi and Tang suggest is that the two terms have different intension which also varies with the context in which they appear, yet with varying intension, they might return the same referent (Cantonese). While scholars may cite the previous literature to establish that fangyan/dialect and yuyan/language are not opposing notions, there is also a common belief that they are. And it is the notion of incompatibility that marks the recent controversy over whether Cantonese is a dialect or language, with the exclusive (not inclusive) or being used.

\section{Conclusion}

Other myths dispelled in PCNNJ include that Cantonese lost out to Mandarin as the national language of China, in which Sun Yat-sen played a key role, and also that Cantonese is recognized by the United Nations (or UNESCO) as a language. Some of these myths are not just factually wrong but also malign a person ${ }^{13}$. It is on ethical grounds that they should be dismissed. However, from a descriptive point of view, a common belief, be it right or wrong, is valued for the effect it produced, especially when the topic concerned is that of "one's feeling." The two factors of mutual intelligibility and politics should not be conceived simply as a pendulum swinging between academic clarity and power supremacy. Just as folk etymology causes language change, the "folk beliefs" (used in a neutral sense) may also have an influence on how a linguistic concept is formed. As noted by Trask (2013: 48), the trend toward regional fragmentation among dialects has been overtaken by recent developments in transport and communication. Here, we further see that the conceptualization of such linguistic terms as "dialect" or "language" is also determined in a more "popularized" manner with the rise of social media and the likes of The Huffington Post. The article mentioned in the beginning of this paper was posted on January 24 and removed nine days later, as a result of the netizens' efforts. Summing up, the battle over Cantonese languagehood as seen in Hong Kong in this era is a battle of minds. What complicates the debate is not just the linguistic phenomena but also the way they are interpreted.

\section{Acknowledgements}

The authors gratefully acknowledge the support by the National Social Science Foundation of China for the project "Studies of Global Chinese Grammar" (11\&ZD128). We would also like to thank the anonymous reviewers for their good comments.

\section{References}

Australian Academy of the Humanities \& Chinese Academy of Social Sciences (1987). Zhongguo Yuyan Dituji [Language Atlas of China]. Hong Kong: Longman.

Bauer, R. S. (1987). Kadai Loanwords in Southern Chinese Dialects. Transactions of International Conference of Orientalists in Japan, 95-111.

Bauer, R. S. (2000). Hong Kong Cantonese and the Road Ahead. In D. C. S. Li, A. Lin, \& W. T. Tsang (Eds.), Language and Education in Postcolonial Hong Kong (pp. 35-58). Hong Kong: Linguistic Society of Hong Kong.

Bell, R. T. (1976). Sociolinguistics: Goals, Approaches and Problems. London: Batsford.

Bloomfield, L. (1933). Language. New York: Henry Holt.

\footnotetext{
${ }^{13}$ While in general Hong Kong people view Dr. Sun in a positive light, an acquaintance of the first author has a low opinion of him for "his involvement in the national-language vote."
} 
Bo, Y. (1979). Zhongguoren Shigang [A Historical Outline of the Chinese People]. Taipei: Sing-Kuang Book Company Ltd.

Bo, Y. (2002). Zhongguoren Shigang Shang: Bo Yang Jingxuanji 31 [A Historical Outline of the Chinese People Book One: Selected Works of Bo Yang 31]. Taipei: Yuan-Liou Publishing.

Chambers, J. K., \& Trudgill, P. (1998/2004). Dialectology. Cambridge: Cambridge University Press. http://dx.doi.org/10.1017/CBO9780511805103

Chin, W. (2010). Zhongwen Qiyi [Uprising of the Chinese Language]. Hong Kong: Enrich Publishing.

Chin, W. (2012). Jijiu Zhongwen Chuji [First-aid Treatment on the Chinese Language First Collection]. Hong Kong: Arcadia Press.

Chishima, E. (1983). Guangzhou Fangyan Xingcheng de Yanjiu [Studies of the Formation of Guangzhou Dialect]. Chiba: Reitakudaigaku Chugokugogaku Kenkyushitsu.

Crystal, D. (2008). A Dictionary of Linguistics and Phonetics (6th ed.). Oxford: Blackwell. http://dx.doi.org/10.1002/9781444302776

Dang, S. L. (1980). Xianggang Shumianyu de Guifanhua Wenti [Problem of Standardization of Hong Kong's Written Language]. Studies in Chinese Linguistics, 1, 79-87.

DeFrancis, J. (1984). The Chinese Language: Fact and Fantasy. Honolulu: University of Hawaii Press.

Fasold, R. (1984). The Sociolinguistics of Society. Oxford: Blackwell.

Feng, S. (2009). On Modern Written Chinese. Journal of Chinese Linguistics, 37, 145-161.

Feng, S. (2010). Lun Yuti de Jizhi ji qi Yufa Shuxing [On Mechanisms of Register System and Its Grammatical Property]. Zhongguo Yuwen, 5, 400-412.

Ferguson, C. (1959). Diglossia. Word, 15, 325-340.

Fishman, J. (1967). Bilingualism with and without Diglossia; Diglossia with and without Bilingualism. Journal of Social Issues, 23, 29-38. http://dx.doi.org/10.1111/j.1540-4560.1967.tb00573.x

Groves, J. (2008). Language or Dialect-or Topolect? A Comparison of the Attitudes of Hong Kongers and Mainland Chinese towards the Status of Cantonese. Sino-Platonic Papers, 179, 1-103.

Ho, R. M. W. (2008). Yue Du [Cantonese Pronunciation]. Hong Kong: Crystal Window Books.

Hou, J. (2002). Xiandai Hanyu Fangyan Gailun [An Outline of Modern Chinese Dialects]. Shanghai: Shanghai Jiaoyu Chubanshe.

Huang, C. T. J. (to appear). Syntactic Analyticity and Parametric Theory. In A. Li (Ed.), Chinese Syntax in a Cross-Linguistic Perspective. Oxford/New York: Oxford University Press.

Institute of Linguistics of the Chinese Academy of Social Sciences, Institute of Ethnology and Anthropology of the Chinese Academy of Social Sciences, \& Language Information Sciences Research Centre of the City University of Hong Kong. (2012). Zhongguo Yuyan Dituji [Language Atlas of China] (2nd ed.). Beijing: Commercial Press.

Kaye, A. (1991). Is English Diglossic. English Today, 7, 8-14.

Klima, E. S. (1972). How Alphabets Might Reflect Language. In J. F. Kavanagh, \& I. G. Mattingly (Eds.), Language by Ear and by Eye (pp. 55-80). Cambridge, MA: MIT Press.

Kloss, H. (1967). Abstand Languages and Ausbau Languages. Anthropological Linguistics, 9, $29-41$.

Kloss, H. (1976). Über ,Diglossie“ [On “Diglossia”]. Deutsche Sprache, 4, 313-323.

Lau, C. F. (2000). Xiandai Yueyu Yuanyu Songmo Yimin Shuo [A Theory that Modern Cantonese Derived from Late Song Dynasty Immigrants]. Proceedings of 7th International Conference on Yue dialects. Beijing: Commercial Press.

Lee, E. E. F. (2001). Profile of the Singapore Chinese Dialect Group. http://www.howardscott.net/4/Swatow_A_Colonial_Heritage/Files/Documentation/Lee\%20Eu\%20Fah.pdf

Li, J. (1990). Yueyu Shi Hanyu Zuqun zhong de Duli Yuyan [Cantonese as an Independent Language in the Family of Chinese Languages]. Proceedings of 2nd Conference on Yue Dialects. Guangzhou: Jinan University Publishers.

Li, X. (1994). Guangdong de Fangyan [Dialects of Guangdong]. Guangzhou: Guangdong Renmin Chubanshe.

Lyovin, A. (1997). An Introduction to the Languages of the World. New York: Oxford University Press.

Mair, V. H. (1991). What Is a Chinese "Dialect/Topolect”? Reflections on Some Key Sino-English Linguistic Terms. SinoPlatonic Papers, 29, 1-31.

Mar-Molinero, C. (2000). The Politics of Language in the Spanish-Speaking World. London: Routledge.

Matthews, S., \& Yip, V. (2011). Cantonese: A Comprehensive Grammar. London: Routledge.

Sebba, M. (2007). Spelling and Society. Cambridge: Cambridge University Press.

http://dx.doi.org/10.1017/CBO9780511486739 
Shi, D., Shao, J., \& Chu, C. Y. (2006). Gangshi Zhongwen yu Biaozhun Zhongwen de Bijiao [Comparison between Hong Kong-Style Chinese and Standard Chinese]. Hong Kong: Educational Publishing House.

Snow, D. (2004). Cantonese as Written Language: The Growth of a Written Chinese Vernacular. Hong Kong: Hong Kong University.

Spolsky, B. (1998). Sociolinguistics. Oxford: Oxford University Press.

Sun, C. (2014). Dialect or Language: A Matter of Language Attitudes. The 22nd Annual Conference of the IACL \& the 26th North American Conference on Chinese Linguistics, College Park, Maryland, 2-4 May 2014.

Tan, C. B. (2005). Chinese in Malaysia. In M. Ember, C. R. Ember, \& I. Skoggard (Eds.), Encyclopedia of Diasporas: Immigrant and Refugee Cultures around the World (pp. 697-706). New York: Kluwer.

Tang, S. W. (2014). Yueyu [Cantonese]. Shawbeat, 1, 51.

Trask, R. L. (2013). Language Change (Language Workbooks). Oxon: Routledge.

Trousdale, G. (2010). An Introduction to English Sociolinguistics. Edinburgh: Edinburgh University Press.

Tutengzi (2010). Yueyu Shi Fangyan Haishi Yuyan, Zhe Shi Ge Huai Wenti [Whether Cantonese Is a Dialect or Language, This Is a Bad Question]. http://web.archive.org/web/20110910141502/http://totemz.z.infzm.com/2010/07/18/fang1yan2/

Wardhaugh, R. (1998). An Introduction to Sociolinguistics (3rd ed.). Oxford: Blackwell.

Yuan, J. et al. (1960). Hanyu Fangyan Gaiyao [An Outline of the Chinese Dialects]. Beijing: Wenzi Gaige Chubanshe.

Yuan, J. et al. (2001). Hanyu Fangyan Gaiyao [An Outline of the Chinese Dialects] (2nd ed.). Beijing: Yuwen Chubanshe.

Yue-Hashimoto, A. (1976). South Chinese Dialects-The Tai Connection. Computational Analyses of Asian \& African Languages, 6, 1-9.

Yue-Hashimoto, A. (1991). The Yue Dialects. In W. S. Y. Wang (Ed.), Languages and Dialects of China (Journal of Chinese Linguistics Monograph 3) (pp. 237-293). Berkeley: Project on Linguistic Analysis.

Zaakjin (2014). Bouwu Gwongdungwaa, Msai Gong Jyunjan [Protecting Cantonese Needs No Justification]. http://www.vjmedia.com.hk/articles/2014/02/04/62205

Zeng, Z. (2008). Xianggang Guanyongyu Yanjiu [A Study of Idiomatic Expressions in Hong Kong Cantonese]. Hong Kong: City University of Hong Kong Press.

Zhan, B. (1991). Hanyu Fangyan ji Fangyan Diaocha [Chinese Dialects and the Dialect Investigation]. Wuhan: Hubei Jiaoyu Chubanshe.

Zhan, B. (2002). Guangdong Yue Fangyan Gaiyao [An Outline of Yue Dialects in Guangdong]. Guangzhou: Jinan University Press. 
Scientific Research Publishing (SCIRP) is one of the largest Open Access journal publishers. It is currently publishing more than 200 open access, online, peer-reviewed journals covering a wide range of academic disciplines. SCIRP serves the worldwide academic communities and contributes to the progress and application of science with its publication.

Other selected journals from SCIRP are listed as below. Submit your manuscript to us via either submit@scirp.org or Online Submission Portal.
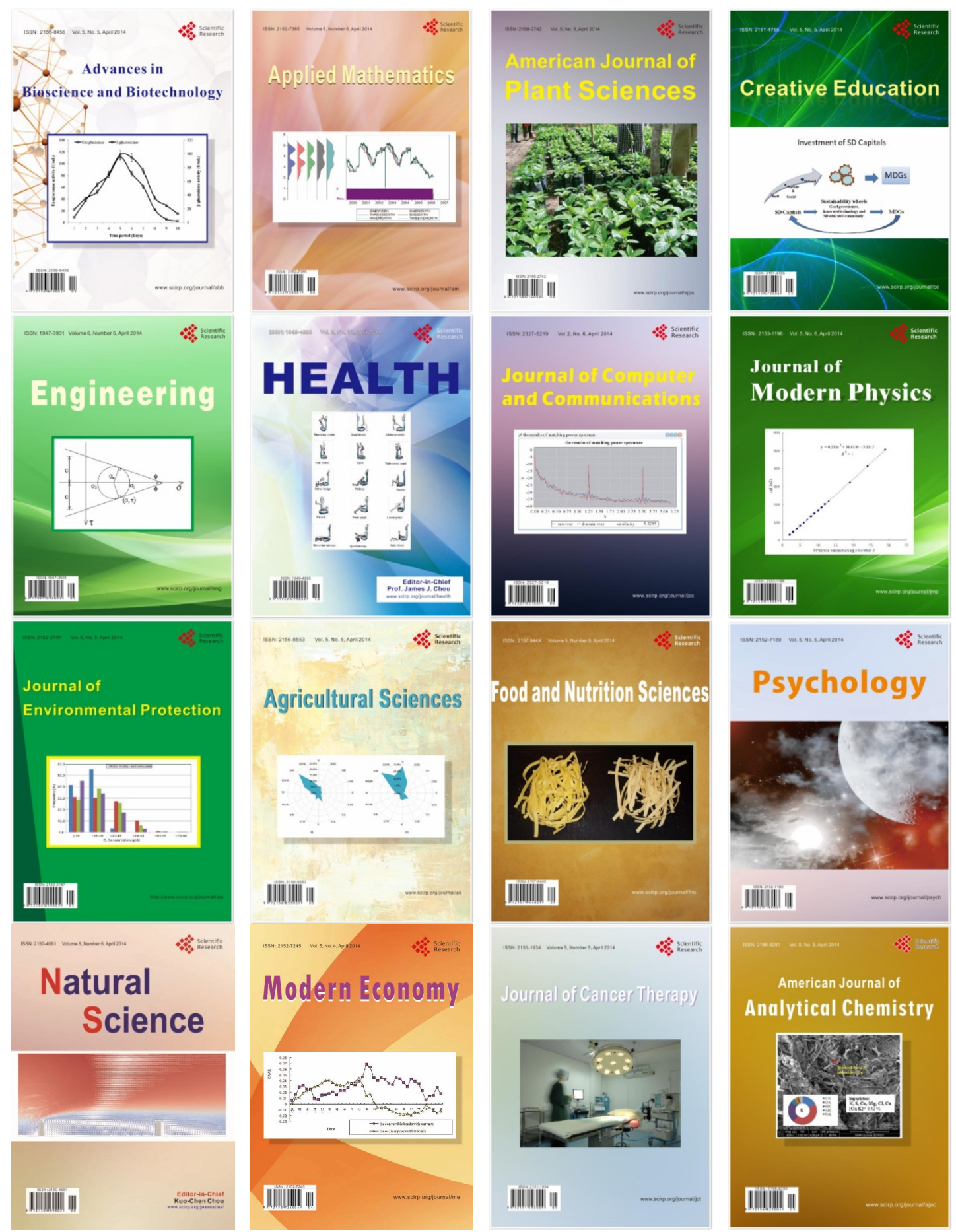